\title{
An evaluation of association between pre-hospital care with injury severity scores among survivors of road traffic accidents in a north Indian setting
}

\author{
Dr.Ravi Kant Singh ${ }^{1}$, Prof. Ashish Kumar ${ }^{2}$, Prof. G.K.Singh ${ }^{3}$, Prof. Santosh \\ Kumar $^{4}$, Dr.Nidhi Singh ${ }^{5}$ \\ 1Deptt. of Orthopaedics, King George's Medical University, Lucknow (Uttar Pradesh) India \\ 2Deptt. of Orthopaedics, King George's Medical University \\ 3 Founder Director, AIIMS, Patna, Bihar, \\ 4Deptt. of Orthopaedics, King George's Medical University, \\ 5Research Scholar,
}

\begin{abstract}
Objective: To compare the AIS and ISS scores according to pre-hospital care received among the subjects of trauma victims

Methods: This was a cross-sectional study conducted in a trauma centre of north Indian tertiary care hospital. The detailed history of the subjects was taken and AIS and ISS scores were calculated for each subject. The subjects who got accident with a vehicle and admitted in the centre were included in the study. The burned and subjects $<12$ years were excluded from the study.

Results: A total of 869 subjects were included in the study and majority were males (81.5\%). Most of the subjects received pre-hospital care (76.1\%). The AIS was significantly $(p=0.02)$ higher who received pre-

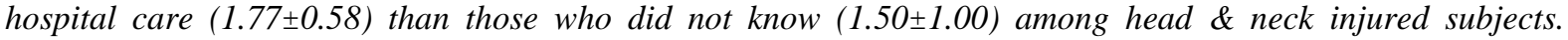
Similar observation was found among the subjects of face and extremities injured. The ISS was lower among those who did not receive pre-hospital care $(5.71 \pm 2.64)$ compared with who received $(6.18 \pm 2.61)$. The ISS was significantly $(p=0.0001)$ different among the subjects who received pre-hospital care, did not received and unknown injuries.
\end{abstract}

Conclusion: The pre-hospital care is an important factor for the survival of injured subjects. Specific strategy should be made to provide the pre-hospital care at the site of victims.

Key words: Pre-hospital care, trauma, strategy

\section{Introduction}

Injury scoring systems are designed to accurately assess injury severity, appropriately triage the injured, and develop and refine trauma patient care (Furnival, 1999). Trauma scores quantify the severity and extent of injury, aid with the prediction of survival and subsequent morbidity, (Fani-Salek, 1999) and allow health care providers to communicate in common terms. One disadvantage of injury scoring systems is that patient information is reduced to a simple score, and important details may be lost. To accurately estimate patient outcome, it is necessary to precisely assess the patient's anatomic and physiologic injury, as well as any preexisting medical conditions that can impair the patient's ability to respond to the stress of the injuries sustained.

Characterization and documentation of injury severity are requirements for the evaluation of trauma systems and development of initiative in injury control. The development of valid and useful quality improvement methods, comparisons of therapeutic modalities with the outcomes of trauma patients, collection of basic epidemiologic trauma data and effective use of pre-hospital and inter-hospital triage are major needs in the trauma care system (Brenneman et al, 1998). A prerequisite to meet these needs is the uniform application of severity scales to the trauma patients (Sharma et al, 2003). Current commonly used scales can be grouped according to the type of patient information on which they are based, such as: Physiologic Scores that include vital signs such as pulse, blood pressure, respiratory rate and level of consciousness. Glasgow Coma Scale (GCS), Revised Trauma Scale (RTS), for patients with serious head injuries, Circulation, Respiration, Abdominal/Thoracic, Motor, Speech Scale (CRAMS), Acute Physiology and Chronic Health Evaluation (APACHE), etc. The Injury Severity Score (ISS) is virtually the only anatomical scoring system in use and correlates linearly with mortality, morbidity, hospital stay and other measures of severity.

The present study was designed to compare the AIS and ISS scores according to pre-hospital care received among the subjects of trauma victims in a tertiary care hospital of north India. 


\section{Material And Methods}

This was a cross-sectional study conducted among the subjects admitted in the Trauma centre of KG Medical University, Lucknow. The study was approved by the institutional ethical committee. The informed consent was taken from each subjects/attendant before including in the study. The inclusion criteria was subjects admitted in Trauma Centre suffered injuries due to road traffic accidents. The exclusion criteria were an injury on road without involvement of vehicle (subjects slipping \& falling on the road \& sustaining injury), injury involving a stationary vehicle (subjects getting injured while washing or loading a vehicle), brought dead due to RTA, subjects not giving informed consent (in coma, unconscious, for more than 3 days post injury \& unable to understand or reply due to shock, subjects referred to trauma centre after being treated elsewhere for more than 3 days, burn subjects and subjects under 12 years.

The Abbreviated Injury Scale (AIS) of each injury was determined using Association for Advancement of Automobile Medicine 1990 protocol. Each case was examined in detail and ISS calculated based on the AIS. Other relevant parameters like age, sex, survival status, date \& time of injury and medical interventions done were also recorded. Depending on the type of injury, Abbreviated injury score is calculated for each case. Injuries are ranked on a scale of 1 to 6 , with 1 being minor, 5 severe and 6 an unsurvivable injury. From Abbreviated Injury Score (AIS), Injury severity score is calculated. The Injury Severity Score is an anatomical scoring system that provides an overall score for patients with multiple injuries. Each injury is assigned an Abbreviated Injury Scale score and is allocated to one of six body regions (Head, Face, Chest, Abdomen, Extremities (including Pelvis), and external). Only the highest AIS score in each body region is used. The 3 most severely injured body regions have their score squared and added together to produce the ISS score.

The results are presented in percentages. The association of pre-hospital care with the outcome of trauma was assessed by using Chi-square test. The p-value $<0.05$ was considered significant. All the analysis was carried out by using SPSS 16.0 version (Chicago, Inc. USA).

\section{Results}

Table-1 presents the distribution of the injured subjects according to age and gender. Most of the subjects were between 20-30 years (46.7) followed by 31-40 (21.4\%) and majority were males $(81.5 \%)$.

The majority $(85.2 \%)$ of the subjects received first aid from nearby government hospital followed by nearby private hospital/clinic and at accident place (Fig.1).

The AIS was significantly $(\mathrm{p}=0.02)$ higher who received pre-hospital care $(1.77 \pm 0.58)$ than those who did not

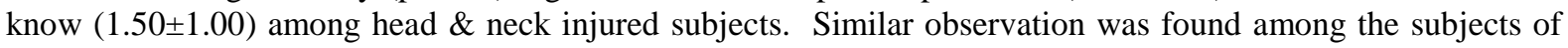
face and extremities injured. The ISS was lower among those who did not receive pre-hospital care (5.71 \pm 2.64$)$ compared with who received $(6.18 \pm 2.61)$. The ISS was significantly $(\mathrm{p}=0.0001)$ different among the subjects who received pre-hospital care, did not received and unknown injuries.

The AIS was significantly different with the different timing of the pre-hospital care in head \& neck, face, chest, abdominal \& pelvic content, extremities and external. The ISS was significantly $(\mathrm{p}=0.002)$ higher among those who received pre-hospital care after 60 minute $(6.19 \pm 2.86)$ than within 30 minute and 30-60 minutes (6.18 \pm 2.52$)$ (Table-3).

Table-1: Distribution of the injured subjects according to age and gender

\begin{tabular}{|l|c|c|}
\hline \multicolumn{1}{|c|}{ Age in years } & $\begin{array}{c}\text { No. } \\
(\mathbf{n = 8 6 9 )}\end{array}$ & \% \\
\hline Age in years & & 13.0 \\
\hline$<20$ & 113 & 46.7 \\
\hline $20-30$ & 406 & 21.4 \\
\hline $31-40$ & 186 & 12.9 \\
\hline $41-50$ & 112 & 4.5 \\
\hline $51-60$ & 39 & 1.5 \\
\hline$>60$ & 13 & \\
\hline Gender & & 81.5 \\
\hline Male & 708 & 18.5 \\
\hline Female & 161 & \\
\hline
\end{tabular}




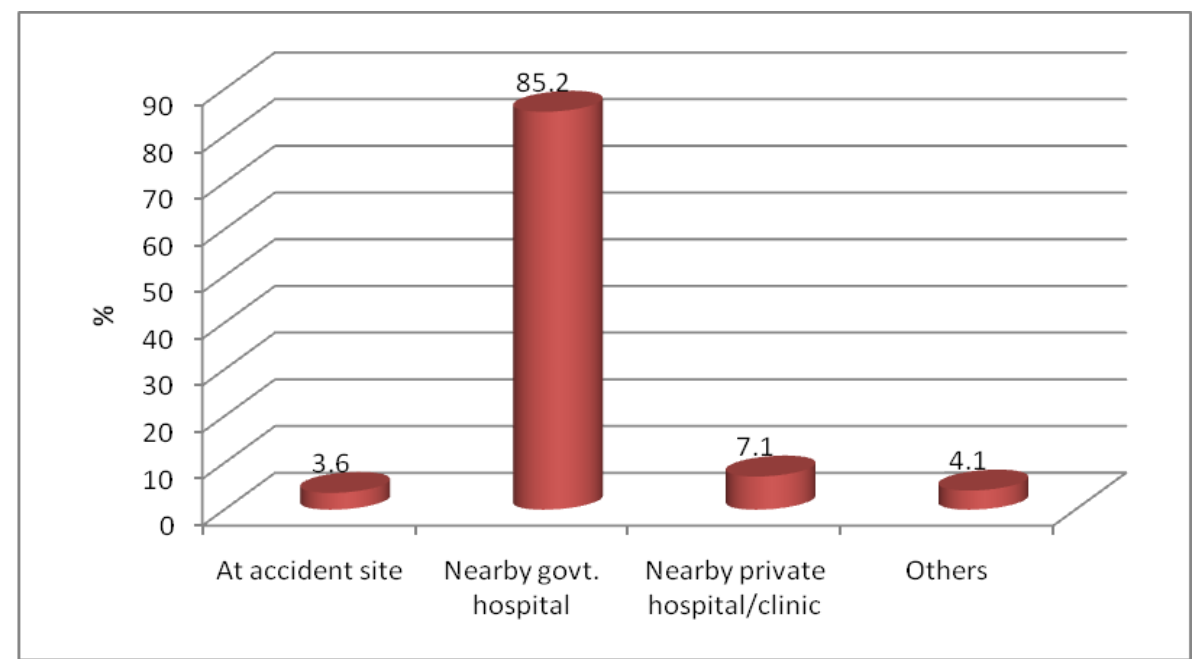

Fig.1: Distribution of the subjects according to place of first AID received

Table-2: Comparison of AIS and ISS scores according to Pre hospital care

\begin{tabular}{|l|r|r|l|l|l|l|l|l|l|}
\hline & & \multicolumn{6}{|c|}{ AIS scores } & \multirow{2}{*}{ ISS } \\
\cline { 1 - 7 } $\begin{array}{c}\text { Pre- } \\
\text { hospital } \\
\text { care }\end{array}$ & $\begin{array}{c}\text { No. } \\
(\mathbf{n = 8 6 9 )}\end{array}$ & $\%$ & $\begin{array}{c}\text { Head \& } \\
\text { Neck }\end{array}$ & Face & Chest & $\begin{array}{c}\text { Abdominal } \\
\text { \& pelvic } \\
\text { content }\end{array}$ & $\begin{array}{c}\text { Extremiti } \\
\text { es }\end{array}$ & External & \\
\hline Yes & 661 & 76.1 & $1.77 \pm 0.58^{2}$ & $1.45 \pm 0.49^{2}$ & $1.59 \pm 0.70$ & $1.08 \pm 0.93^{2}$ & $1.76 \pm 0.52^{2}$ & $1.01 \pm 0.07$ & $6.18 \pm 2.61$ \\
\hline No & 179 & 20.6 & $1.58 \pm 0.61$ & $1.52 \pm 0.50$ & $1.50 \pm 0.53$ & $1.92 \pm 0.76^{3}$ & $1.65 \pm 0.54$ & $1.01 \pm 0.10$ & $5.71 \pm 2.64^{2}$ \\
\hline $\begin{array}{l}\text { Not } \\
\text { known }\end{array}$ & 29 & 3.3 & $1.50 \pm 1.00^{2}$ & $2.00 \pm 0.40^{2}$ & $2.00 \pm 0.65$ & $4.00 \pm 0.16^{2,3}$ & $1.12 \pm 0.35^{2}$ & $1.00 \pm 0.00$ & $7.76 \pm 1.70^{2}$ \\
\hline p-value & & & $0.02^{*}$ & $0.04^{*}$ & 0.52 & $0.001^{*}$ & $0.001^{*}$ & 0.80 & $0.0001^{*}$ \\
\hline
\end{tabular}

${ }^{1}$ ANOVA, *Significant, ${ }^{2} \mathrm{p}<0.05,{ }^{3} \mathrm{p}<0.01$ (Post-hoc comparison test)

Table-3: Comparison of AIS and ISS scores according to time of Pre hospital care

\begin{tabular}{|l|c|c|c|c|c|c|c|c|c|}
\hline $\begin{array}{c}\text { Time of } \\
\text { Pre- } \\
\text { hospital } \\
\text { care }\end{array}$ & \multirow{2}{*}{$\begin{array}{c}\text { No. } \\
(\mathbf{n = 6 6 1})\end{array}$} & \multirow{2}{*}{$*$} & $\begin{array}{c}\text { Head \& } \\
\text { Neck }\end{array}$ & Face & Chest & $\begin{array}{c}\text { Abdominal \& } \\
\text { pelvic content }\end{array}$ & Extremities & External & ISS \\
\hline $\begin{array}{l}\text { Within } \\
30 \\
\text { minutes }\end{array}$ & 185 & 28.0 & $1.79 \pm 0.50$ & $1.49 \pm 0.50$ & $1.40 \pm 0.50$ & $0.43 \pm 0.53$ & $1.76 \pm 0.48$ & $1.01 \pm 0.10$ & $6.19 \pm 2.86$ \\
\hline $\begin{array}{l}30-60 \\
\text { minutes }\end{array}$ & 447 & 67.6 & $1.76 \pm 0.62$ & $1.44 \pm 0.49$ & $1.74 \pm 0.80$ & $1.25 \pm 0.96$ & $1.74 \pm 0.54$ & $1.00 \pm 0.06$ & $6.18 \pm 2.52$ \\
\hline $\begin{array}{l}>60 \\
\text { minutes }\end{array}$ & 29 & 4.4 & $1.92 \pm 0.60$ & $1.97 \pm 0.51$ & $1.92 \pm 0.89$ & $1.94 \pm 0.11$ & $1.99 \pm 0.49$ & $1.29 \pm 0.03$ & $6.99 \pm 2.35$ \\
\hline p-value & & & $0.02^{*}$ & $0.01^{*}$ & $0.02^{*}$ & $0.002^{*}$ & $0.003^{*}$ & $0.004^{*}$ & $0.002^{*}$ \\
\hline
\end{tabular}

${ }^{1}$ ANOVA, *Significant

\section{Discussion}

The present study investigated the association between AIS and ISS with the pre-hospital care received. In our best knowledge, none of the study had correlated these parameters. Common to all RTI studies males are the commonly affected population in our study as males tend to travel more in comparison to females with age group of 20-30 years (Sharma et al, 2002; Sharma et al, 2005). Baker et al introduced the ISS in 1974 as a means of summarizing multiple injuries in a single patient. The ISS is defined as the sum of squares of the highest AIS grade in the 3 most severely injured body regions and ranges from 1-75. An ISS of 75 is assigned to anyone with AIS of 6, as all the AIS 6 injuries are inherently fatal (Sharma et al, 2005).

Every trauma service should review the process and outcome of patient care on monthly basis as recommended by the Joint Commission on Accreditation of Healthcare Organization's (JCAHO) mandated reviews of quality improvement and utilization. Indices of severity and audit criteria are of value in identifying aberrant outcomes or potential problems in patient care, and in prompting remedial action. Strategies for quality improvement in trauma care should involve the policy or process of managing the major trauma victim (Rutledge et al, 1993).

The AP addresses some of the shortcomings of the ISS. It uses the AIS descriptors of anatomic injury, but includes only four body regions: $\mathrm{A}=$ head/brain and spinal cord; $\mathrm{B}=$ thorax/neck; $\mathrm{C}=$ all other serious injuriesother than in the areas of A and B; and D = all non-serious injuries (Furnival, 1999; Fani-Salek, 1999). 
Injuries with an AIS value $>2$, which are defined as serious, are scored for the first three categories above (Furnival, 1999). All minor injuries, defined as AIS scores of $\leq 2$, are classified as non-serious, regardless of their anatomic location (Fani-Salek, 1999). The total AP score is the sum of the square roots of the sum of the squares of the AIS for all individual injuries within a region (Furnival, 1999; Fani-Salek, 1999). This allows the second and third injuries occurring within a given region to be considered in the final AP score, preventing the loss of information that occurs with the ISS (Furnival, 1999). AP is most useful in an inpatient setting and has neither been widely used nor validated for paediatric trauma (Furnival, 1999; Fani-Salek, 1999).

Trauma registries must be founded on complete, accurate data that includes explicit and accurate descriptions of physiologic derangement and injuries as well as accurate injury coding based on ICD-9-CM codes, by the clinicians in medical record.

\section{Conclusion}

The pre-hospital care is an important factor for the survival of injured subjects. Specific strategy should be made to provide the pre-hospital care at the site of victims.

\section{Source of funding: \\ Conflict of interest:}

\section{References}

[1]. Furnival RA, Schunk JE. ABCs of scoring systems for pediatric trauma. Pediatr Emerg Care 1999; 15:215-223.

[2]. Fani-Salek MH, Totten VY, Terezakis SA. Trauma scoring systems explained. Emerg Med 1999; 11:155-166.

[3]. Brenneman FD, Boulonger BR, McLellan BA, et al. Measuring injury severity: time for a change? J Trauma Injury, Infection and Critical Care, 1998; 44 (4): 580-584.

[4]. Sharma BR, Harish D, Singh G et al. Pattern of Head Injuries in Fatal Road Traffic Accidents. Bahrain Med. Bulletin. 2003 ; 25 (1): $22-25$.

[5]. Sharma BR, Gautam CS, Singh R. Road Traffic Accidents Vis-à-vis Problems Related to Ageing. Hospital Today 2002; VII (10): 523- 528.

[6]. Sharma BR. The Injury Scale - a valuable tool for forensic documentation of trauma. J Clinical Forensic Medicine. 2005 ; 12 (1): 21 -28 .

[7]. Sharma BR, Gupta M, Bangar S. NISS a valuable tool for trauma scoring on autopsy. J Biological Sciences $2005 ; 8$ (7): 995 - 1000.

[8]. Rutledge R, Fakhry S, Baker C, et al. Injury severity grading in trauma patients: a simplified technique based upon ICD - 9 coding. J Trauma 1993; 35: 497.

[9]. Furnival RA, Schunk JE. ABCs of scoring systems for pediatric trauma. Pediatr Emerg Care 1999; 15:215-223. 